Bartın Üniversitesi

Eğitim Fakültesi Dergisi

Cilt 6, Sayı 3, s. 1153 - 1165, Ekim 2017

BARTIN - TÜRKIYE

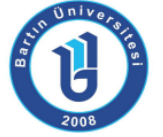

ISSN: 1308-7177
Bartin University

Journal of Faculty of Education

Volume 6, Issue 3, p. 1153 - 1165, October 2017

BARTIN - TURKEY

\title{
Sorgulamaya Dayalı Basit Araç Gereçlerle Yapılan Fizik Etkinliklerinin Fen Öğretmenlerinin Görüşlerine Etkisi
}

\author{
Haki PEŞMAN, Yrd. Doç. Dr., Fırat Üniversitesi, Eğitim Fakültesi, h.pesman@gmail.com \\ ORCID: http://orcid.org/0000-00003-4778-2735 \\ Üzeyir ARI, Araş. Gör. Dr., Fırat Üniversitesi, Eğitim Fakültesi, uzeyirari@gmail.com \\ ORCID: http://orcid.org/0000-00001-8598-4798 \\ Oktay BAYKARA, Prof. Dr., Fırat Üniversitesi, Eğitim Fakültesi, obaykara@firat.edu.tr
}

ORCID: http://orcid.org/0000-00003-4429-0401

Öz: Bu çalışma TUBiTAK tarafından desteklenen "Neşeli Fen Dersleri, Sorgulayan Öğrenci ve Sevilen Bilim" projesine katılan fen bilimleri öğretmenlerinin Basit Araç-Gereçlerle yapılan Etkinliklerle (BAGYE) ilgili görüşlerinde bir değişim olup olmadığını incelemek amacıyla yapılmıştır. Çalışmaya Bingöl, Elazığ, ve Tunceli illerindeki 58 gönüllü fen bilimleri öğretmenleri katılmıştır. Çalışmada uygun örnekleme kullanılmıştır. Öğretmenler proje kapsamında mekanik, termodinamik ve optik konuları gibi fizik konularını kapsayan bazı seçilmiş BAGYE'leri Sorgulamaya Dayalı Öğretimle (SDÖ) yapmışlardır. Çalışmada sadece tek grup vardır ve çalışmanın öncesinde ve sonrasında veri toplama aracı olarak Uzal vd. (2010) tarafından geliştirilen ve 12 maddelik bir Likert ölçeği olan BAGYE'lerle ilgili görüş anketi uygulanmıştır. Aynı zamanda proje sonunda öğretmenlerle odak grup çalışması gerçekleştirilerek nicel veriler nitel verilerle de desteklenmiştir. Sonuç olarak fen öğretmenlerinin BAGYE'lerle ilgili son-test ön-test puanları arasında anlamlı bir fark çıkmasa da bayan fen öğretmenlerinin görüş puanlarının çalışma neticesince bir miktar yükselirken erkek öğretmenlerin görüşlerinde çok az düşme gözlenmiştir.

Anahtar Kelimeler: basit araç-gereçlerle yapılan fizik etkinlikleri, sorgulamaya dayalı öğretim, fen bilimleri öğretmeni eğitimi, fizik eğitimi

\section{Effect of Inquiry Based Hands-on Physics Activities on Views of Science Teachers}

\begin{abstract}
This study was performed to explore whether there is a change in views about handson physics activities of the science teachers participated in the project "Amazing Science Lessons, Inquiring Students, and Popular Science" supported by TUBITAK. 58 volunteer science teachers in Bingöl, Elazığ, and Tunceli provinces of Turkey participated in the study. Convenience sampling was utilized. Teachers performed some selected hands-on activities covering physics contents such as mechanics, thermodynamics, and optics through inquiry teaching. There is one group in the study and the survey with 12 four-point Likert items for measuring views about hands-on activities developed by Uzal et al. (2010) was used just prior and after the treatment. In addition, a focus group interview was conducted after the treatment to support the quantitative data qualitatively. Consequently, although there was not a significant difference between pre-test and post-test scores, there was a slight decrease in views of males while females' views were rising at one level.
\end{abstract}

Key Words: hands-on physics activities, inquiry teaching, science teacher education, physics education 


\section{GíRiş}

İçeriğinde somut ve soyut birçok kavramın yer aldığı fizik konularının etkili bir şekilde anlaşılabilmesi için derslerde etkinliklere yer verilmesi oldukça önemlidir. Bundan dolayı ders kitaplarında da etkinliklere bol bol yer verilmektedir. Ancak bu etkinlikler yapılması gerekenleri adım adım anlatan yönergeler şeklinde sunulmaktadır (Huber ve Moore, 2001). Dolayısıyla etkinliklerin bu şekilde yapıldığı fizik derslerinde öğrenciler bedenen aktif olsalar da zihinsel olarak aktif oldukları pek söylenemez. Hâlbuki etkinliklerde öğrencilerin bedensel olarak aktif oldukları gibi zihinsel olarak ta aktif olmaları istenmektedir (Hake, 1998). Öğrenciler bu şekilde bilgiyi aktif olarak yapılandırabilirler. Etkinlikleri yapmak içinse laboratuvarlarda gelişmiş deney araç-gereçlerinin bulunması şart değildir. Öğrencilerin çevrelerinden bulabilecekleri basit malzemelerle de etkinlikleri yapmaları mümkündür. Ancak buradaki asıl amacın sadece basit araç gereçlerle etkinlik yapmak değil de etkinliğin arkasındaki kavramların etkili bir şekilde öğretilmesi olduğu düşünülürse, etkinliklerin adım adım yönergeler şeklinde (yemek kitabı formatı) değil de Sorgulamaya Dayalı Öğretimle (SDÖ) işlenmesi önerilmektedir (Huber ve Moore, 2001). Bu şekilde öğretmenlerin deneye, gözleme ve keşfe önem vermesiyle, öğrencilerin soru sorma, araştırma yapma, hipotez kurma ve en önemlisi ortaya çıkan sonuçları yorumlayabilme becerileri (bilimsel süreç becerileri) gelişebilmektedir (Balagun, ve Odubunni, 1991). SDÖ ilk olarak Amerikan Ulusal Fen Eğitimi Standartları (NSES) tarafından geleneksel fen öğretimine bir alternatif olarak önerilmiştir (NRC, 2000). Bilim hem bilgi hem de bir süreç işidir. Yani bilim insanları bilimsel süreç becerileri kullanarak bilimsel bilgi üretmektedir (Rao-Kumari, 2008, s.3). SDÖ'de de öğrenciler bilim insanı gibi davranırlar (NRC, 2000, ss. 21-33). SDÖ’nün beş temel özelliği NRC (2000, ss. 21-33) tarafından şu şekilde önerilmektedir:

1. Öğrenci bilimsel odaklı soruları kullanarak araştırmaya başlar,

2. Öğrenci soruları cevaplamada kanıta öncelik verir,

3. Öğrenci kanıttan yola çıkarak açıklamalarını formüle eder,

4. Öğrenci bilimsel bilgi ile açıklamaları arasında bağlantı kurar ve

5. Öğrenci açıklamalarını savunur ve sunar.

Rehberliğin miktarına göre SDÖ yönteminin dört farklı düzeyi vardır (Schwab, 1962; Colburn, 2000; Settlage ve Southerland, 2007 aktaran Blanchard vd., 2010): sıfır seviyesi doğrulayıcı sorgulama, birinci seviye - yapılandırılmıs sorgulama, ikinci seviye - rehberli sorgulama ve üçüncü seviye - açık sorgulama. Doğrulayıcı sorgulamada araştırma sorusu ve veri toplama süreci öğrencilere öğretmen tarafından sağlanır. Bu düzeyde öğrenciler etkinlikler sırasında sonuçlardan bihaberdirler; ancak, öngörülen bir sonuca varmaları amacıyla öğretmenin rehberliği söz konusudur. Doğrulayıcı sorgulamada etkinlikler "yemek kitabı" formatında sunulmaktadır. Yapılandırılmış sorgulamada öğretmen öğrencilere soruyu ve izleyecekleri yöntemi verir; ancak sonuçları öğrenciler yorumlar. Rehberli sorgulamadaysa öğrencilere sorular sunulmuştur; ancak hipotezlerin nasıl test edileceğini (yöntem) de öğrenciler belirler. Son düzey olan açık sorgulamadaysa hipotezlerin kurulacağı araştırma sorusu dahi öğrenciler tarafından oluşturulmaktadır. Yani öğrenciler araştırmanın neredeyse tamamından sorumludurlar.

SDÖ yöntemiyle derslerin işlenmesi öğrencilerin bilimsel bilginin nasıl üretildiği ve bilim insanlarının hangi aşamalardan geçerek onu ürettiği konusunda fikir sahibi olmalarını sağlar. SDÖ ile derslerin işlenmesiyle öğrencilerin fen derslerinde başarılarının ve bilimsel süreç becerilerinin arttığı ve fene karşı tutum ve motivasyonlarının geliştiği sıkça rapor edilmiştir (Açışlı ve Turgut, 2011; Bilir, 2015; Demirkıran, 2016; Karapınar, 2016; Kaya ve Yılmaz, 2016; Keçeci, 2014; Kırıktaş, 2014; Nuhoğlu ve Yalçın, 2006; Öz, 2015; Ünlü, 2015; Yaşar ve Duban, 2009). Ancak etkin bir SDÖ için öğretmenlerin bu yöntemi tam olarak uygulayabilmesi gerekir. Alan yazında SDÖ'nün bahsedilen faydalarına rağmen öğretmenlerin sınıflarında SDÖ'yü kullanmadıkları belirtilmiştir. Buna göre öğretmenler SDÖ’yü tam olarak bilememekte veya uygulamasını zor bulmaktadırlar 
(Huber ve Moore, 2001; Welch-Klopfer vd., 1981). Bu problem ise bu çalışmanın esas amacının zeminini oluşturmaktadır. TÜBiTAK 4005 çağrı numarasıyla desteklenen ilgili projede Bingöl, Elazığ ve Tunceli'deki fen öğretmenlerinin BAGYE'leri SDÖ ile yapmaları amaçlanmıştır. Bu amaca dönük olarak bazı fizik konularını içerecek şekilde seçilmiş olan Basit Araç Gereçlerle Yapılan Etkinlikler (BAGYE) öğretmenlere SDÖ ile yaptırılmıştır. Bu bağlamda bu çalışmada BAGYE'lerle ilgili öğretmen görüşleri irdelenmektedir. Öğretmenlerin BAGYE’lerle ilgili görüşlerinin cinsiyetleriyle olan ilişkisi de irdelenmiştir.

\section{YÖNTEM}

\subsection{Yöntem}

Bu çalışmada TÜBITAK 4005 çağrı numarasıyla desteklenen projeye katılan fen bilimleri öğretmenleri ile birlikte BAGYE'ler SDÖ yöntemiyle işlenmiştir. Daha sonra bu etkinliklerin SDÖ yöntemiyle işlenmesiyle öğretmenlerin BAGYE'lerle ilgili görüşlerinde değişiklik olup olmadığı nicel olarak incelenmiştir. Dolayısıyla tek denekli araştırma türlerinden ABA deseni kullanılmıştır (Büyüköztürk vd., 2014, s. 217). Ayrıca uygulama sonrasında öğretmenlerle odak grup çalışması (Bogdan ve Biklen, 2007, ss. 109-112) yapılarak nicel veriler nitel olarak ta desteklenmiştir. Dolayısıyla bu çalışma karma bir çalışma olup gömülü desen türündedir (Büyüköztürk vd., 2014, ss. 246-248). Bu desen başka bir çalışmada da ardışık açıklayıcı desen olarak isimlendirilmektedir (Robson, 2015, s. 204).

\section{2. Çalışma Grubu}

Bu çalışmanın ulaşılabilir evrenini 2013-2014 eğitim-öğretim yılının güz döneminde Elazığ, Bingöl ve Tunceli illerinde görev yapmakta olan fen bilgisi öğretmenleri oluşturmaktadır. Öğretmenlerin ilgili projeye katılabilmesi için bu illerde bulunan Milli Eğitim Müdürlükleri tarafından tanıtım toplantıları düzenlenmiştir. Projeyle ilgilenen öğretmenlerden başvuru formu doldurmaları istenmiştir. Başvuru formu dolduran öğretmenlerden gönüllü olan 58 fen bilgisi öğretmeni bu projeye seçilmiştir. Dolayısıyla bu çalışmada örnekleme tekniği olarak rastgele olmayan uygun örnekleme tekniği kullanılmıştır (Fraenkel ve Wallen, 1996, ss. 90 - 113). Ayrıca öğretmenlerin seçimi sırasında cinsiyet ve illere göre eşitliğin sağlanmasına çaba gösterilmiştir. Buna göre Bingöl Elazığ ve Tunceli illerinden çalışmaya katılan öğretmen sayıları sırasıyla 18, 18 ve $13^{\prime}$ tür. Erkek ve bayan öğretmen sayıları ise 34 ve 24 'tür. Odak grup çalışması etkinlikler bittikten sonra çeşitli nedenlerle çıkmak durumunda kalan öğretmenlerin haricinde kalan 15 civarı öğretmenle gerçekleştirilmiştir.

\subsection{Veri Toplama Araçları}

Öğretmenlerin BAGYE'lerle ilgili görüşleri: Projeye katılan öğretmenlerin BAGYE'lerle ilgili görüşlerini incelemek için uygulanan bu anket Uzal, Erdem, Önen ve Gürdal (2010) tarafından geliştirilmiştir. Bu anket 12 maddeden ve dört likert türü seçenekten oluşmaktadır. Likert seçenekler şu şekildedir: "Kesinlikle Katılıyorum", "Katılıyorum", "Katılmıyorum", "Kesinlikle Katılmıyorum" ve anket maddelerinin değerlendirmesinde kesinlikle katılıyorum 4, katılıyorum 3, katılmıyorum 2 ve tamamen katılmıyorum 1 puan olarak kodlanmıştır. Görüşlerin hangi düzeyde olduğunu tespit etmek için "aralık genişliği = dizi genişliği / yapılacak grup sayısı => (41) / $4=>3 / 4=>0,75$ " değeri dikkate alınarak değerlendirme aralıkları belirlenmiştir (Uzal vd., 2010). Buna göre değerlendirme aralıkları Tablo 1'de görülmektedir. Uzal vd. (2010) tarafından geliştirilen anket için Cronbach alpha güvenirlik katsayısı araştırmacılar tarafından 0,92 olarak hesaplanmıştır. Bu çalışmada ise güvenirlik katsayı ön test için 0,84 son test için ise 0,86 olarak bulunmuştur. 
Tablo 1

Anket Maddelerini Değerlendirmek için Hesaplanan Değerlendirme Aralıkları

\begin{tabular}{lll}
\hline Puan & Seçenek & Değerlendirme aralı̆̆ \\
\hline 4 & Kesinlikle Katılıyorum & $3,28-4,00$ \\
3 & Katılıyorum & $2,52-3,27$ \\
2 & Katılmıyorum & $1,76-2,51$ \\
1 & Tamamıyla Katılmıyorum & $1,00-1,75$ \\
\hline
\end{tabular}

Odak grup çalışması: Proje ekibi tarafından hazırlanan etkinlikler sorgulamaya dayalı olarak işlendikten sonra öğretmenlerle birlikte odak grup çalışması yapılmıştır. Ancak görüşme sırasında etkinlikler tamamlanmış olduğundan sadece 15 civarı öğretmen görüşmeye katılabilmiştir. Odak grup çalışmasında şu sorular öğretmenlere yöneltilmiştir:

a. Derslerinizde deney ve etkinliklere yer vermeyi düşünüyor musunuz?

b. Bu tür deney ve etkinlikleri neden yaptırmayı/yaptırmamayı düşünüyorsunuz?

c. Bu deney ve etkinlikleri dersinizde nasıl sunmayı düşünüyorsunuz?

\section{4. İşlem}

TÜBITAK tarafından desteklenen bu proje kapsamında toplam 15 etkinlik gerçekleştirilmiştir (Tablo 2'ye bakınız).

Tablo 2

Projede İşlenen Etkinliklerin Kazanımlarla Eşleştirilmesi (Arı, Peşman, Baykara ve Sunar, 2016'dan alınmıştır)

\begin{tabular}{|c|c|c|}
\hline No & Etkinlik & Kazanım \\
\hline 1 & Patates ve Pipet & $\begin{array}{l}\text { Gaz basıncının katı ve sıvı basıncı kadar büyük olabileceğin } \\
\text { açıklar. }\end{array}$ \\
\hline 2 & Damlalığın Dansı & $\begin{array}{l}\text { a. Pascal prensibini açıklar. } \\
\text { b. Kaldırma kuvvetini açıklar. }\end{array}$ \\
\hline 3 & İnce İp Mi? Kalın İp Mi? & Katılarda basıncı açıklar. \\
\hline 4 & Nem Ölçer & $\begin{array}{l}\text { Buharlaşma olayının bir soğutma olayı olduğu sonucuna } \\
\text { varır. }\end{array}$ \\
\hline 5 & Kardan Adamımız Erimesin. & $\begin{array}{l}\text { a. Isının iletim yollarından birinin ışıma yoluyla } \\
\text { olduğunu söyler. } \\
\text { b. Maddelerin ısıyı farklı hızlarda ilettiğini sonucuna } \\
\text { varır. }\end{array}$ \\
\hline 6 & Dumanın Yönü & Konveksiyon yoluyla ısı iletimini açıklar. \\
\hline 7 & $\begin{array}{l}\text { Ateşle Yaklaşmak Tehlikeli } \\
\text { Değildir! }\end{array}$ & Suyun özısının çok büyük olduğunun farkına varır. \\
\hline 8 & Görünmezlik Mümkün Müdür? & Işığın kırılmasını açıklar. \\
\hline 9 & Sınır Açısı Hesaplama. & Tam yansımayı açıklar. \\
\hline 10 & Periskop & Işığın yansımasını açıklar. \\
\hline 11 & Elektrik Motoru & $\begin{array}{l}\text { Bir manyetik alanda üzerinden akım geçen tele etki eden } \\
\text { elektromanyetik kuvveti açıklar. }\end{array}$ \\
\hline 12 & Elektrik Tesisatı Neden Yanar? & Üzerinden akım geçen direncin ısındığını fark eder. \\
\hline 13 & Sigortanın Önemi & $\begin{array}{l}\text { Elektriği güvenli bir şekilde kullanmak için sigortanın } \\
\text { önemini vurgular. }\end{array}$ \\
\hline 14 & $\begin{array}{l}\text { Pürüzsüz Yüzeyde Sürtünme Olur } \\
\text { Mu? }\end{array}$ & Sürtünme kuvvetinin elektriksel bir olay olduğunu açıklar. \\
\hline 15 & Ses Illetimi & Sesin hangi ortamlarda daha iyi iletildiğini açıklar. \\
\hline
\end{tabular}


Bu etkinliklerden ilk altısı 2013-2014 eğitim öğretim yılının güz döneminin hemen başlangıcında, diğer dokuzu ise bu dönemin sonunda işlenmiştir. Etkinliklerin bu şekilde zamana yayılmasıyla uygulamanın kalıcılık etkisinin artırılması hedeflenmiştir. Bu etkinlikleri SDÖ yoluyla gerçekleştirmek için öncelikle öğretmenlerden beşer kişilik gruplar oluşturmaları istenmiştir. Her bir etkinliğin başlangıcında da öğretmenlere takip ettikleri aşamaları yazmaları için çalışma kağıtları verilmiştir. Bundan sonra etkinliğin başlangıcında öğretmenlere ilgi çekici bir problem sunulmuş ve problemi çözmek amacıyla gruplarında birbirleri ile tartışmaları istenmiştir. Bu tartışmadan sonra çözüm için önerdikleri hipotezlerini çalışma kağıtlarına yazmaları istenmiştir. Ardından etkinlikteki bağımlı değişken, bağımsız değişken, kontrol edilen ve edilemeyen değişkenleri belirleyip yazmaları istenmiştir. Daha sonra etkinlik için gerekli olan basit araçgereçler öğretmenlere sağlanmış ve öğretmenlerden deneyi gerçekleştirmeleri istenmiştir. Yaptıkları gözlemi ve bu gözlemin hangi fizik kavramlarıyla ilgili olduğunu çalışma kağıtlarına yazmaları istenmiştir. Öğretmenlerden daha sonra gözlemlerini yorumlamaları ve kurdukları hipotezleri reddedip reddetmediklerini tartışmaları ve çalışma kağıdına yazmaları istenmiştir.

\subsection{Verilerin Analizi}

Görüş anketinin verilerini analiz etmek için SPSS (Versiyon 21) paket programı yardımıyla betimsel istatistik yöntemleri ve bağımlı örneklem t-testi analizi ile grup içi ve gruplar arası karma varyans analizi (Mixed Between-Within Subjects Analyses of Variance, Pallant, 2007, ss. 266-274) kullanılmıştır. Öğretmenlerle yapılan odak grup çalışmasının analizi için ise ses kayıtlarının transkript edilmesiyle sözlü olarak ifade edilen öğretmen görüşleri kağıda aktarılmış ve incelenmiştir. Nitel verilerin incelemesi üç araştırmacı tarafından, içerik analizi yoluyla yapılmıştır.

\section{BULGULAR}

\subsection{Kayıp Veri Analizi}

Bu çalışmaya 58 fen bilimleri öğretmeni katılmıştır. Ancak bu öğretmenlerden dokuzu yapılan projenin ikinci aşamasına katılamamıştır. Dolayısıyla son teste de katılamamışlardır. Bu kayıp deneklerin son test puanlarının değerlendirilmesinde bir problem oluşturup oluşturmadığını tespit edebilmek için projenin ikinci aşamasında bulunan ve bulunmayan öğretmenlerin ön test puanları karşılaştırılmıştır. Bu kapsamda projenin ikinci aşamasında bulunan öğretmenlerin " 0 ", bulunmayan öğretmenlerin "1" olarak numaralandırıldığı bir bağımsız değişken oluşturulmuştur. Görüş anketi ön test puanları ise bağımlı değişken olarak kullanılmıştır. Projenin ikinci aşamasında bulunmayan öğretmenlerin sayısı bulunan öğretmenlerin sayısından önemli ölçüde düşük olmasından dolayı parametrik olmayan bir test olan Mann-Whitney $U$ testi ön testi analizi yapmak için kullanılmıştır. Burada projenin ikinci aşamasında bulunmayan ve bulunan öğretmenlerin öt test puanları arasında anlamlı bir farkın olmadığını belirten sıfır hipotezi test edilmiştir. Sonuç olarak sıfır hipotezinin reddedilmediği dolayısıyla projenin ikinci aşamasında bulunan ve bulunmayan öğretmenlerin ön test puanları arasında istatistiksel olarak anlamlı bir farklılığın olmadığı gözlenmiştir $(z=-.78, p=.44)$. Bundan dolayı projenin ikinci aşamasında bulunmayan öğretmenlerin çalışmanın verilerinin analizini etkilemediği varsayılabilir. Bu nedenle burada sadece projenin ikinci aşamasına katılan öğretmenlerin son test puanları kullanılarak veri analizi yapılmıştır. Buna ek olarak bu öğretmenlerin kayıp ön test puanları ortalama puanlarla yer değiştirilmiştir.

\subsection{Betimsel İstatistik}

Tablo 3'de fen bilimleri öğretmenlerinin cinsiyetleri de dikkate alınarak BAGYE'ler hakkındaki görüşlerine dayalı betimsel istatistik bulguları sunulmaktadır. Öncelikle çarpıklık ve basıklık değerleri her bir grup için normal dağılımın sağlandığını göstermektedir. 
Tablo 3

Fen Bilimleri Öğretmenlerinin BAGYE’lerle Illgili Görüşleri Anketinin Ön ve Son Testi için Betimsel Istatistik Analizi

\begin{tabular}{llllllllc}
\hline Anket & Grup & N & X & s & Min. & Maks. & Çarpıklık & Basıklık \\
\hline Ön Test & Erkek & 29 & 3,62 & 0,28 & 2,75 & 4,00 & $-0,978$ & 1,894 \\
& Bayan & 20 & 3,63 & 0,31 & 3,08 & 4,00 & $-0,333$ & $-1,023$ \\
& Toplam & 49 & 3,62 & 0,29 & 2,75 & 4,00 & $-0,641$ & 0,321 \\
\multirow{5}{*}{ Son Test } & Erkek & 29 & 3,59 & 0,30 & 3,00 & 4,00 & $-0,172$ & $-0,813$ \\
& Bayan & 20 & 3,69 & 0,35 & 3,08 & 4,00 & $-0,637$ & $-1,129$ \\
& Toplam & 49 & 3,63 & 0,32 & 3,00 & 4,00 & $-0,313$ & $-1,106$ \\
\hline
\end{tabular}

Minimum ve maksimum değerler ise özellikle bayanlar lehine olmak üzere görüş puanlarının oldukça yüksek olduğunu göstermektedir. Erkek ve bayan fen bilimleri öğretmenlerinin görüş anketi ön test puanlarının birbiriyle neredeyse aynı olduğu da görülmektedir (erkek $=3,62$; bayan $=3,63$ ). Ancak görüş anketi son testinde ortalamaların bayanlar için arttığı; bayların ise ortalamalarının bir miktar düştüğü gözlenmiştir (erkek = 3,59; bayan $=3,69$ ).

\section{3. Çıkarımsal istatistik}

Projeye katılan öğretmenlerin BAGYE'lerle ilgili görüşlerinde bir ilerleme olup olmadığını incelemek için öncelikle bağımlı örneklem t-testi kullanılmıştır. Bulgular Tablo 4'de görüldüğü gibidir.

Tablo 4

Projenin Ikinci Aşamasına Katılan Öğretmenlerin Görüş Anketi Ön ve Son Test Puanlarının Bağımlı Örneklem t-testi Sonuçları

\begin{tabular}{lcccccc}
\hline Görüş Anketi & $\mathbf{N}$ & $\mathbf{X}$ & $\mathbf{s}$ & $\mathbf{t}$ & $\mathbf{d f}$ & $\mathbf{p}$ \\
\hline Ön test & 49 & 3,62 & 0,292 & $-0,193$ & 48 & 0,848 \\
Son test & 49 & 3,63 & 0,046 & & & \\
\hline
\end{tabular}

Tablo 4'de görüldüğü üzere görüş anketinin ön ve son test ortalamalarının neredeyse aynı (GA ön-test ortalaması = 3,62; GA son-test ortalaması = 3,63; t = -0,193, p=0,85) olduğu görülmektedir. Bunun böyle olması öğretmenlerin BAGYE'lerle ilgili başlangıçta zaten çok olumlu görüşlere (değerlendirme aralığı 3.28 - 4.00 aralığında olan seçenek "Kesinlikle Katılıyorum") sahip olmasından kaynaklanabilir. Uygulamadan sonra son test puanlarında çok küçük bir artış olmuş fakat puanlar zaten yüksek kabul edilebilecek bir seviyede olmasından dolayı bu sonuç ortaya çıkmış olabilir. Öğretmenlere uygulanan görüş anketinin ön ve son test puanlarını kıyaslamak için kullanılan bağımlı örneklem t-testi sonucunda istatistiksel olarak anlamlı bir farklılık ortaya çıkmamıştır. Ancak "erkek ve bayan öğretmenlerin görüşlerindeki değişim acaba benzer midir?" sorusunu incelemek üzere grup içi ve gruplar arası karma varyans analizi (Mixed Between-Within Subjects Analyses of Variance, Pallant, 2007, ss. 266-274) yapılmıştır. Grup içi ve gruplar arası karma varyans analizi için gruplar arası bağımsız değişken cinsiyet (erkek ve bayan), grup içi bağımsız değişken zaman (ön test - son test) iken bağımlı değişken ise görüş anketi puanlarıdır. Analizi gerçekleştirmeden önce gerekli sayıltılar kontrol edilmiştir. Analize mani olabilecek uç değerlerin incelenmesinde herhangi bir problem ortaya çıkmamıştır. Çarpıklık ve basıklık değerleri kontrol edildiğinde onlarında Tablo 3'te görüldüğü gibi +2 ve -2 aralığında olduğu gözlenmiştir. Buna göre verilerin normal dağılım gösterdiği söylenebilir (George ve Mallery, 2003, ss. 98-99). Ayrıca uç değerlerin olmaması ve gruplardaki örneklem sayısının nispeten eşit olması varyans analizi sonuçlarını yeterince sağlam kılmaktadır (Tabachnick ve Fidell, 2007, p. 202). Zaten hata varyanslarının eşitliğinin test edildiği Levene Testinde istatistiksel olarak anlamlı bir fark gözlenmemiştir ( $p>0,05$ ). Dolayısıyla erkek ve bayan fen 
bilimleri öğretmenleri için varyansların eşit olduğu varsayılabilir. Sayıltılar kontrol edildikten sonra grup içi ve gruplar arası karma varyans analizi gerçekleştirilmiştir (Tablo 5'e bakınız).

Tablo 5

Grup İçi ve Gruplar Arası Karma Varyans Analizi Sonuçları

\begin{tabular}{lccccccc}
\hline Etki & $\begin{array}{c}\text { Wilks } \\
\text { Lambdası }\end{array}$ & $\mathbf{F}$ & $\begin{array}{c}\text { Hypothesis } \\
\text { df }\end{array}$ & $\begin{array}{c}\text { Error } \\
\text { df }\end{array}$ & $\boldsymbol{p}$ & $\begin{array}{c}\text { Kısmi } \\
\text { eta kare }\end{array}$ & $\begin{array}{c}\text { Gözlenen } \\
\text { güç* }^{*}\end{array}$ \\
\hline Zaman & 0,997 & 0,144 & 1,000 & 47,000 & 0,71 & 0,003 & 0,066 \\
Zaman*Cinsiyet & 0,978 & 1,068 & 1,000 & 47,000 & 0,31 & 0,022 & 0,173 \\
\hline
\end{tabular}

* 0,05 alpha kullanılarak hesaplanmıştır.

Sonuç olarak uygulamalar sırasında erkek ve bayan fen bilimleri öğretmenlerinin BAGYE'lerle ilgili görüşlerindeki değişimler arasında istatistiksel olarak anlamlı bir farklılık olmasa da bayanlar lehine pratikte küçük etki büyüklüğüne sahip bir farklılık bulunmuştur $(F(1,47)=$ $1,068 ; p=0,31$; Wilks Lambdası $=0,978 ;$ kısmi eta kare $=0,022)$. Etki büyüklügü küçük olan bu etkileşimin grafiği de şu şekildedir (Şekil 1).

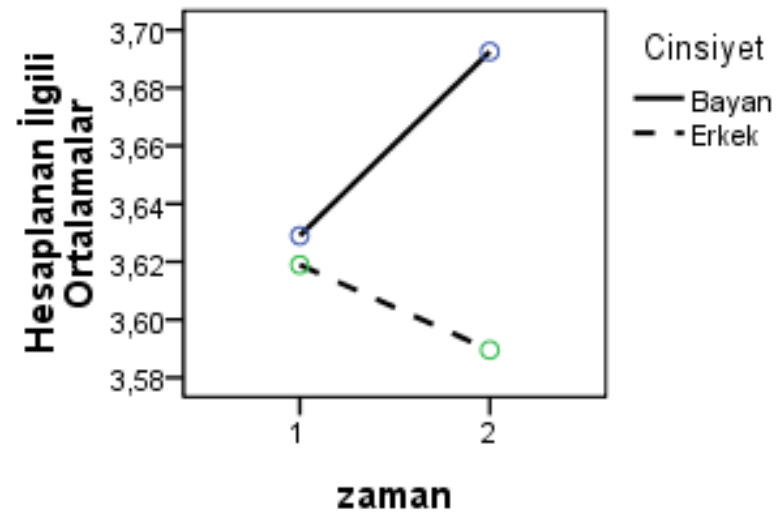

Şekil 1. Erkek ve bayan fen bilimleri öğretmenlerinin görüş anketi ön ve son testlerinin zamana göre etkileşim grafiği

Şekil 1'deki grafiğe bakıldığında da bayanların ortalamasının son testte artarken erkeklerin bir miktar düştüğü görülmektedir. Yani erkekler de bayanlar gibi ilerleme göstermiş olsaydı genel olarak (toplamda) son test görüş puanları ön test görüş puanlarından anlamlı bir şekilde yüksek çıkabilirdi.

\subsection{Odak Grup Çalışmasının Değerlendirilmesi}

Fen bilimleri öğretmenlerinin BAGYE'leri SDÖ yoluyla gerçekleştirmesini takiben onların BAGYE'ler hakkındaki görüşleri yapılandırılmış görüşme yoluyla odak grup çalışması şeklinde ortaya çıkarılmıştır. Odak grup çalışmasındaki görüşme etkinliğin sonunda 15 civarı öğretmenle bir saatlik bir süre içerisinde yapılmıştır. Öğretmenlere aşağıdaki sorular yöneltilmiştir.

a. Derslerinizde deney ve etkinliklere yer vermeyi düşünüyor musunuz?

b. Bu tür deney ve etkinlikleri neden yaptırmayı/yaptırmamayı düşünüyorsunuz?

c. Bu deney ve etkinlikleri dersinizde nasıl sunmayı düşünüyorsunuz?

Bütün gruba yönlendirilen her bir soruya her öğretmen cevap vermemiş, sadece söz alanlar cevap vermiştir. Öğretmenlerin bu cevapları transkript edilmiştir. Sonra transkriptler okunurken oluşturulan temalar doğrultusunda renklendirme yoluyla üç araştırmacı tarafından kodlamalar yapılmıştır. Sonuçta öğretmenlerin BAGYE'ler hakkındaki görüşleriyle ilgili olarak Tablo 6 oluşturulmuştur. 
Tablo 6

Fen Bilimleri Öğretmenleriyle Yapılan Odak Grup Tartışmasının Iç̧erik Analizi Sonuçları

\begin{tabular}{|c|c|}
\hline Tema & Kodlar \\
\hline $\begin{array}{l}\text { Daha önce fen derslerinde deneye yer verip } \\
\text { vermedikleri }\end{array}$ & $\begin{array}{l}\text { Hayır } \\
\text { Evet; ama nadiren } \\
\text { Evet; ama ben yapıyordum }\end{array}$ \\
\hline $\begin{array}{l}\text { Önceden deney yaptırmamalarının / az } \\
\text { yaptırmalarının gerekçeleri }\end{array}$ & $\begin{array}{l}\text { Laboratuvar yokluğu } \\
\text { Mevcut laboratuvarların uygun olmayan } \\
\text { koşulları (bodrum kat, havasız, karanlık ve } \\
\text { kirli olması) } \\
\text { Malzeme yokluğu } \\
\text { Deneyleri öğrencilere nasıl yaptıracağını } \\
\text { bilmemek } \\
\text { Öğrenci kontrolü, sınıf yönetimi kaygısı } \\
\text { Zaman yönetimi } \\
\text { Öğretim programını yetiştirememe kaygısı } \\
\text { Derslerinde deney yapan öğretmene deney } \\
\text { yapmayandan daha fazla önem verilmemesi }\end{array}$ \\
\hline $\begin{array}{l}\text { Ögrretmenler bundan sonra derslerinde } \\
\text { BAGYE'lere yer verecek mi? }\end{array}$ & $\begin{array}{l}\text { Bundan sonra BAGYE'lere yer verebilirim. } \\
\text { BAGYE'leri yaptırmak için motivasyonum } \\
\text { daha fazla. }\end{array}$ \\
\hline $\begin{array}{l}\text { Bundan sonra derslerinde BAGYE'lere neden } \\
\text { yer verecekleri }\end{array}$ & $\begin{array}{l}\text { Öğretmenin basit ve rahat temin edilebilecek } \\
\text { malzemelerle deneyleri yaptırabilmesi } \\
\text { Deney yaptırma hususunda öğretmenlerin } \\
\text { öz-yeterliklerinin bu projeyle beraber artmış } \\
\text { olması } \\
\text { Artık sınıfta bile deney yaptırabileceklerini } \\
\text { düşünmeleri } \\
\text { BAGYE'leri bu şekilde işlemenin öğrencilere } \\
\text { bilgi ve beceri kazandırdığına inanılması } \\
\text { Bu şekilde öğrencilerin derslerde } \\
\text { sorgulamaya başlaması } \\
\text { Bu şekilde öğrencilerin bilime karşı olumlu } \\
\text { tutum kazanacağına inanılması }\end{array}$ \\
\hline
\end{tabular}

Tablo 6' da da görüldüğü gibi fen bilimleri öğretmenlerinin BAGYE'lerle ilgili görüşlerinin içerik analiziyle incelenmesi sonucu; öğretmenlerin önceden derslerinde BAGYE'lere yer verip vermedikleri, bununla ilgili gerekçeleri, bundan sonra BAGYE'lere yer verip vermeyecekleri ve gerekçeleri ortaya konulmuştur. Buna göre laboratuvar olmaması, mevcut laboratuvarların kötü koşulları, laboratuvarlarda malzeme eksikliği, sınıf yönetimi ve öğretim programını yetiştirememe kaygısı gibi nedenlerden dolayı öğretmenlerin önceden fen derslerinde BAGYE'lere yer vermedikleri, az yer verikleri ya da gösteri deneyi şeklinde yer verdikleri görülmektedir. Bu çalışma neticesinde basit araç gereçlerle sınıflarda bile deney yaptırabilmeleri, deneyleri nasıl işlemeleri gerektiğini görmeleri, öğretmenlerin bu konudaki öz yeterliklerinin artması, öğrencilere bilime karşı olumlu tutum kazandıracağına inanmaları vb. gibi nedenlerden dolayı bu öğretmenler bundan sonra derslerinde BAGYE'lere yer verebileceklerini ve bunun için motivasyonlarının yüksek olduğunu dile getirmişlerdir.

\section{SONUÇ, TARTIŞMA VE ÖNERILER}

Bu çalışmada BAGYE'lerin SDÖ ile fen bilimleri öğretmenlerine yaptırılması sonucunda bu öğretmenlerin BAGYE'lere karşı görüşlerinin daha olumlu olacağı beklenmiştir. Ancak yapılan 
analizlerde hem istatistiksel olarak hem de pratikte anlamlı bir fark gözlenememiştir. Bu durum hem son test hem de ön test puanlarının oldukça olumlu olmasından kaynaklanmış olabilir. Zira fen bilimleri öğretmenlerinin BAGYE'lere karşı görüşlerinin oldukça yüksek olduğu rapor edilmiştir (Uzal vd., 2010). Her ne kadar nicel olarak incelendiğinde BAGYE 'ye karşı görüşlerde bir gelişim gözlenemese de nitel incelemeler aslında öğretmenlerin BAGYE'lere karşı olumlu görüş kazandıkları yönündedir. Mesela bazı öğretmenler projeden önce derslerinde laboratuvar yokluğu gibi bahanelerle etkinlikler yaptırmadıklarını, fakat proje sürecinde aslında derslerinde etkinliklere yer verebileceklerini fark ettiklerini dile getirmiştir.

Son test - ön test puanları arasındaki farkın cinsiyetle bir ilişkisi olup olmadığı ayrıca incelenmiş ve bayanların görüşlerinde bir miktar yükseliş olurken bayların görüşlerinde bir miktar azalma olduğu gözlenmiştir. Bu etkileşim istatistiksel olarak anlamlı olmasa da pratikte küçük büyüklükte bir etkileşimdir. Buna göre erkek öğretmenler de bayan öğretmenler gibi ilerleme göstermiş olsaydı son test puanları ön test puanlarına göre anlamlı bir farklılıkta gösterebilirdi. Uzal vd. (2010) çalışmalarında erkek ve bayan öğretmenlerin (sınıf ve fen bilimleri) görüşlerinde istatistiksel olarak bir fark gözlemlememiştir. Pratikte bir fark olup olmadığını ise rapor etmemişlerdir. Ancak çıkarımsal istatistik analizlerinde verdikleri değerler kullanılarak etki büyüklükleri hesaplandı. Buna göre bu çalışmada olduğu gibi istatistiksel olarak bir fark görmeseler de pratikte küçük büyüklükte bir fark hesaplanmaktadır (kısmi eta kare $=0,02$ ) ve bu fark bu çalışmada olduğu gibi bayanlar lehinedir. Burada dikkat edilecek hususlardan bir tanesi de erkek ve bayan öğretmenlerin ön test puanları neredeyse aynı iken son test puanlarında bayanlar lehine bir farklılaşmanın ortaya çıkışıdır. Bu durum BAGYE'lerin SDÖ ile işlenmesinin bayanlar lehine neden farklı bir etki gösterdiği sorusunu akla getirmektedir. Acaba bayan fen öğretmenleri erkek fen öğretmenlerine kıyasla sınıf yönetiminde kendilerini daha mı yetersiz görüyorlar ve BAGYE'lerle sınıf yönetimlerini daha iyi mi yapacaklarını düşünüyorlar? Zira odak grup çalışmasında öğretmenler daha önceden zaman yönetimi, deney organizasyonu, özgüven (öz-yeterliği kastetmiş olabilir) ve sınıf yönetimi gibi faktörlerden dolayı derslerinde etkinliklere yer vermediklerini dile getirmişlerdir. Proje süresince bazı öğretmenler bu kaygılarının ortadan kalktığını dile getirmişlerdir. Alan yazına bakıldı̆ıında Türkiye'de fen öğretmen adayları üzerine yapılmış çalışmalar erkek ve bayan fen öğretmen adaylarının sınıf yönetimleri ile ilgili algılarında anlamlı bir farklılık ortaya koyamamıştır (Savran ve Çakıroğlu, 2003; Yılmaz ve Çavaş, 2008). Her ne kadar fen öğretmenleri değil de fen öğretmen adaylarının sınıf yönetimi ile ilgili algılarına dair çalışmalar yapılmış olsa da; erkek öğretmenlere kıyasla bayan fen öğretmenlerinin BAGYE'lere karşı olumlu görüş geliştirmelerinin nedeni belki de sınıf yönetimleriyle ilgili algıları değil de konu alan bilgisi gibi başka bir faktör de olabilir. Zira Lee (1995) fen bilgisi zayıf olan öğretmenlerin öğrencilere sınıf olarak etkinlik yaptırmaktan kaçındıklarını rapor etmiştir. Özetle bayan fen öğretmenlerinin baylara kıyasla BAGYE'lere karşı olumlu görüş geliştirmesinin arkasında birçok faktör olabilir. Bu çalışma bunun nedenini ortaya koymamaktadır ancak başka araştırmacılar fen öğretmenlerinin BAGYE'lere karşı görüşlerinin cinsiyete göre neden farklı olduğunu ya da bir uygulama sonucunda neden farklılaştığını (bu çalışmada olduğu gibi) hangi faktörlerin açıkladığını inceleyebilirler. Bu tür çalışmalar ilgili alan yazına ciddi katkılar sağlayacaktır.

\section{TEŞEKKÜR}

Bu çalışma TÜBITAK tarafından 113B241 proje numarasıyla desteklenmiştir. 


\section{KAYNAKLAR}

Açışlı, S. ve Turgut, Ü. (2011). The examination of the influence of the Materials Generated in Compliance with $5 \mathrm{E}$ learning model on physics laboratory applications. Internetional Online Journal of Educational Sciences, 3(2), 562-593.

Arı, Ü., Peşman, H. vd. (2016). Fen bilimleri öğretmenlerinin bilimsel süreç becerilerinin gelişimi. Uluslararası Türk Eğitim Bilimleri Dergisi, 4(7), 44-52.

Balagun, T.A. ve Odubunni, O. (1991). The effect of lecture teaching methods on cognitive achievement in integrated science. Journal Research in Science Teaching, 28, 213-224.

Bilir, U (2015). Fen bilimleri öğretiminde araştırma ve sorgulamaya dayalı öğrenme sürecinin öğrencilerin akademik başarısına etkisi. (Yayımlanmamış Yüksek Lisans Tezi). Uludağ Üniversitesi, Bursa.

Blanchard, M. R., Southerland, S. A. vd. (2010). Is inquiry possible in light of accountability?: A quantitative comparison of the relative effectiveness of guided inquiry and verification laboratory instruction. Science Education, 94(4), 577-616.

Bogdan, R. C. ve Biklen, S. K. (2007). Qualitative research for education: An introduction to theories and methods. Boston, MA: Pearson Education, Inc.

Büyüköztürk, Ş., Çakmak, E. K. vd. (2014). Bilimsel araştırma yöntemleri. Ankara, Türkiye: Pegem Akademi.

Colburn, A. (2000). An inquiry primer. Science Scope, 23(6), $42-44$.

Demirkıran, Z. A. (2016). Fen bilimleri dersinde araştırma-sorgulamaya dayalı uygulamaların etkileri. (Yayımlanmamış Yüksek Lisans Tezi). İstanbul Aydın Üniversitesi, İstanbul.

Fraenkel, J. R. ve Wallen, N. E. (1996). How to design and evaluate research in education. McGraw-Hill.

George, D. ve Mallery, P. (2003). SPSS for Windows step by step a simple guide and referance 11.0 update (4th Ed.). Boston, MA: Pearson Education.

Hake, R. R. (1998). Interactive-engagement versus traditional methods: A six-thousand-student survey of mechanics test data for introductory physics courses. American Journal of Physics, 66 (1), 64.

Huber, R. A. ve Moore, C. J. (2001). A Model for Extending Hands-On Science to Be Inquiry Based. School Science and Mathematics, 101(1), 32-42.

Karapınar, A. (2016). Sorgulamaya dayalı öğrenme ortamının öğretmen adaylarının bilimsel süreç becerileri, sorgulama becerileri ve bilimsel düşünme yetenekleri üzerindeki etkisi. (Yayımlanmamış Yüksek Lisans Tezi). Celal Bayar Üniversitesi, Manisa.

Kaya, G. ve Yılmaz, S. (2016). Açık sorgulamaya dayalı öğrenmenin öğrencilerin başarısına ve bilimsel süreç becerilerinin gelişimine etkisi. Hacettepe Üniversitesi Eğitim Fakültesi Dergisi, 31(2), 300-318.

Keçeci, G. (2014). Araştırma ve sorgulamaya dayalı fen öğretiminin öğrencilerin bilimsel süreç becerilerine ve tutumlarına etkisi. (Yayımlanmamış Doktora Tezi). Fırat Üniversitesi, Elazığ.

Kırıktaş, H. (2014). Sorgulamaya dayalı fen öğretim yönteminin fen öğretmen adaylarının bilimsel süreç becerilerine, akademik başarılarına ve biyoloji laboratuvar uygulamalarına yönelik tutumlarına etkisi. (Yayımlanmammış Yüksek Lisans Tezi). Dokuz Eylül Üniversitesi, İzmir.

Lee, O. (1995). Subject matter knowledge, classroom management, and instructional practices in middle school science classrooms. Journal of Research in Science Teaching, 32(4), 423440. 
Pallant, J. (2007). SPSS survival manuel: A step-by-step guide to data analysis using SPSS for windows. New York, NY: Open University Press.

National Research Council (2000). Inquiry and the national science education standards: A guide for teaching and learning. Washington, DC: National Academy Press.

Nuhoğlu, H. ve Yalçın, N. (2006). Fizik laboratuarı çalışmalarında "öğrenme halkası modelinin" öğrenci başarısına etkisi. Türk Fen Eğitimi Dergisi, 3(2), 50-65.

Öz, R. (2015). Araştırma ve sorgulamaya dayalı etkinliklerle desteklenmiş bilim merkezi uygulamalarının 7. sınıf öğrencilerinin akademik başarılarına, bilim okuryazarlıklarına ve sorgulayıı düşünme becerilerine etkisi. (Yayımlanmamış Yüksek Lisans Tezi). Marmara Üniversitesi, İstanbul.

Rao, D. B. ve Kumari, U. N., (2008). Science process skills of school students. Arora Offset Press, Laxmi Nagar, Delhi-92.

Robson, C. (2015). Bilimsel araştırma yöntemleri: Gerçek dünya araştırması. (Çev. Şakir Çınkır ve Nihan Demirkasımoğlu) Ankara: ANI Yayıncılık.

Savran, A. ve Çakıroğlu, J. (2003). Differences between elementary and secondary preservice science teachers' perceived efficacy believes and their classroom management believes. The Turkish Online Journal of Educaitonal Tezhnology, 2(4), 15-20.

Schwab, J. J. (1962). The teaching of science as enquiry. In J. J. Schwab ve P. F. Brandwein, The teaching of science. Cambridge, MA: Harvard University Press.

Settlage, J. ve Southerland, S. A. (2007). Teaching science to all children: Using culture as a starting point. New York: Routledge.

SPSS Statistics (Version 21) (Computer software). Armonk, NY: IBM.

Tabachnick, B. G., \& Fidell, L. S. (2007). Using multivariate statistic. Boston, MA: Pearson Education, Inc.

Welch, W.W., Klopfer, L.E. vd. (1981). The role of inquiry in science education: Analysis and recommendations, Science Education, 65, 33-50.

Uzal, G., Erdem, A. vd. (2010). The evaluation of teachers' opinions about hands-on science experiments and the performed in-service training. Necatibey Faculty of Education Electronic Journal of Science and Mathematics Education, 4(1), 64-84.

Ünlü, Z.K. (2015). Fen ve teknoloji dersinde araştırma-sorgulamaya dayalı öğrenmenin öğretim teknolojileri ile desteklenmesine yönelik bir eylem araştırması. (Yayımlanmamaış Doktora Tezi). Gazi Üniversitesi, Ankara.

Yaşar, Ş. ve Duban, N. (2009). Students' opinions regarding to the inquiry-based learning approach. Elementary Education Online, 8(2), 457-475.

Yılmaz, H. ve Çavaş, P. H. (2008). The effect of the teaching practice on pre-service elementary teachers' science teaching efficacy and classroom management beliefs. Eurasia Journal of Mathmatics, Science, ve Technology Education, 4(1), 45-54. 


\section{SUMMARY}

It is very important to include activities in lessons so that the physics topics in which many concrete and abstract concepts are contained can be understood effectively. Therefore, there are plenty of hands-on activities in the textbooks. However, these activities are usually presented as a step-by-step guide (Huber and Moore, 2001), and, in the physics classes where activities are done in such a way, students are not mentally active although they are physically active. However, students are desired to be mentally active as they are physically active for an effective physics instruction (Hake, 1998). Students are supposed to construct knowledge actively in this way and it is not necessary to have advanced laboratory equipment to perform such activities. Materials that students can find easily in their surroundings may be also used effectively. Moreover, such hands-on activities are suggested to be carried out through inquiry teaching rather than as a step-by-step guidebook (a cookbook form) if the main purpose is to effectively teach the concepts behind the activities (Huber and Moore, 2001). In this way, the ability of the students to raise questions, construct hypothesis, explore, and interpret the findings (science process skills) are possible to be developed (Balagun, and Odubunni, 1991). The inquiry teaching was first proposed by the American National Science Education Standards (NSES) as an alternative to traditional science teaching (NRC, 2000).

Although teachers are supposed to benefit from inquiry teaching, it is however stated in the literature that they rarely use it in their classes. Indeed, they do not know it exactly or find it difficult to apply it. This problem is the basement of this study. It was aimed that the science teachers in Bingöl, Elazığ and Tunceli provinces in Turkey have an opportunity to carry out hands-on activities through inquiry teaching in the project named "Amazing Science Lessons, Inquiring Students and Popular Science" supported by The Scientific and Technological Research Council of Turkey (TUBITAK).

For this purpose, some hands-on activities selected to include several physics topics were carried out by science teachers through inquiry instruction. In this context, opinions of the teachers about the hands-on activities, if it changed during the project, and if male and female teachers' opinion changed similarly were examined in this study. The experimental design was a single-sample experimental design (Büyüköztürk et al., 2014, p. 217). In addition, after the activities, a focus group interview with the teachers was performed as well to support the quantitative research qualitatively. Therefore, this study is a mixed type research study with embedded pattern (Büyüköztürk et al., 2014, pp. 246-248). 58 volunteer science teachers from Elazığ, Bingöl and Tunceli provinces of Turkey were selected and participated in the project in the fall semester of 2013-2014 academic year. That is, convenience sampling, a non-random sampling technique, was used as the sampling technique (Fraenkel and Wallen, 1996, pp. 90 - 113). Also, special attention was paid to selection of the teachers to ensure equality according to gender and provinces. The scale developed by Uzal et al., (2010) was used to examine views of the science teachers about hands-on science activities. It consists of 12 four-point Likert items. The Cronbach alpha coefficient was calculated as 0.86 separately for the pre-test and the post-test. In addition, the following questions were directed to the teachers in the focus group interview:

a. Do you think that you should include experiments and activities in your classes?

b. Why do you think you should have/not have such experiments and activities?

c. How do you think about presenting these experiments and activities in your class?

In the study, it had been expected that views of the science teachers about the hands-on activities would be increased as a result of the treatment in which some selected hands-on physics activities were carried out through inquiry teaching. However, no statistically and practically significant progress was observed in the analysis. This may be due to the fact that both the post-test and pre-test scores were quite high. Science teachers' views on the hands-on activities are observed to be very high according to the literature as well (Uzal et al., 2010). Although quantitative analysis of the views about hands-on activities yielded no progress, qualitative data indicates some signs of progress. For example, some teachers stated that they had not included hands-on physics activities in their classes before the project because of some issues such as lack of a laboratory, but they realized in the course of the project that they could actually include hands-on activities in their lessons. 
Whether the difference between the pre-test and post-test scores was a gender-related relationship was explored as well, and it was observed that there was a slight decrease in the views of the males while there was some increase in the views of females. Although this interaction was not statistically significant, it was practically significant with a small-effect size. According to this, if the male teachers had demonstrated progress like female teachers, the post-test scores could have been significantly different from the pre-test scores. One of the points to be noticed here is that the pre-test scores of the male and female teachers were almost the same while difference of the post test scores was in favor of the females. The factors behind this relationship was not in the scope of this study. However, there seems to be some hints about such factors. For example, some issues the science teachers face about classroom management may be a factor although studies on science teacher candidates in Turkey did not reveal a significant difference in the perceptions of male and female science teacher candidates regarding classroom management (Savran and Çakıroğlu, 2003; Yılmaz and Çavaş, 2008). The science teachers mentioned about some issues in focus group interview such as careless laboratories in the basement floors, lack of materials, and failure to train the curricula. Such factors may be the factors influencing views about hands-on activities. Therefore, future research seems to be required to shed light to explain what factors are behind science teachers' views on hands-on activities. Those factors may ensure researchers to interpret the relationship between the views on hands-on activities and gender of the teachers as well. 